\title{
Iron chelators do not reduce cold-induced cell injury in the isolated perfused rat kidney model
}

\author{
Miranda Bartels-Stringer ${ }^{1}$, Jack F. M. Wetzels ${ }^{2}$, Alfons C. Wouterse ${ }^{1}$, Eric Steenbergen ${ }^{3}$, \\ Frans G. M. Russel ${ }^{1}$ and Cornelis Kramers ${ }^{1}$ \\ ${ }^{1}$ Department of Pharmacology-Toxicology, ${ }^{2}$ Department of Nephrology and ${ }^{3}$ Department of Pathology, \\ Radboud University Nijmegen Medical Centre, Nijmegen, The Netherlands
}

\begin{abstract}
Background. In vitro, cold-induced injury is an important contributor to renal tubular cell damage. It is mediated by iron-dependent formation of reactive oxygen species and can be prevented by iron chelation. We studied whether iron chelators can prevent coldinduced damage in the isolated perfused rat kidney (IPK) model both after cold perfusion (CP) and after cold storage (CS). We hypothesized that in the CP model iron-dependent cold-induced injury is more pronounced, since oxygen is constantly provided.

Methods. The IPK was either flushed with University of Wisconsin (UW) solution and stored for 4, 18 or $24 \mathrm{~h}$ at $4^{\circ} \mathrm{C}$ or perfused during $4 \mathrm{~h}$ at $4^{\circ} \mathrm{C}$ with UW for machine perfusion. The iron chelators $2,2^{\prime}$-dipyridyl or desferal, or the negative control $4,4^{\prime}$-dipyridyl were added during the cold perfusion. Kidney function was measured during $2 \mathrm{~h}$ reperfusion at $37.5^{\circ} \mathrm{C}$ and compared to a control group (without cold preservation). Results. Compared to control perfusion, kidney function was decreased in all experimental protocols. glomerular filtration rate and $\mathrm{FR}\left(\mathrm{H}_{2} \mathrm{O}\right)$ were significantly decreased, while $\mathrm{FE}$ (gluc) and $\mathrm{FE}(\mathrm{Na})$ were higher after $4 \mathrm{~h} \mathrm{CS}$ and CP. After $4 \mathrm{~h} \mathrm{CP}$, also renal vascular resistance was increased. Addition of 2,2'-dipyridyl did not improve kidney function after either CS or CP. Prolonged periods of CS worsened kidney function. The addition of 2,2'-dipyridyl or desferal did not improve kidney function after longer periods of CS.

Conclusions. Addition of an iron chelator to the preservation solution UW did not improve kidney function after both CS and CP. Iron chelation is not able to prevent cold-induced damage in the isolated perfused rat kidney.
\end{abstract}

Correspondence and offprint requests to: Dr Cornelis Kramers, Department of Pharmacology and Toxicology, Radboud University Nijmegen Medical Centre, P.O. Box 9101, 6500 HB Nijmegen, The Netherlands. Email: C.Kramers@pharmtox.umen.nl
Keywords: cold perfusion; cold storage; iron; isolated perfused kidney; renal injury

\section{Introduction}

It has long been thought that the immediate graft injury after transplantation is predominantly caused by ischaemia/reperfusion. In recent years, in vitro studies have shown that not only ischaemia/ reperfusion but also cold per se may induce cell damage. In liver cells [1] as well as in kidney cells [2], it has been found that antioxidants can inhibit this pure hypothermic injury. In vitro experiments show that this cold-induced cell injury is triggered by a cold-induced increase in cellular chelatable iron [3], followed by an iron-dependent formation of reactive oxygen species. In vitro, cold-induced injury can be limited by iron chelators or oxygen deprivation. The effect of iron chelators in this setting is impressive. [Cold preservation of a primary culture of rat proximal tubular cells (PTC) for $24 \mathrm{~h}$ followed by rewarming results in marked cell injury and features suggestive for apoptosis.] Addition of an iron chelator during cold preservation prevents cell damage completely [4]. It is, however, not known whether irondependent cold-induced damage plays an important role in the injury that occurs during transplantation of the kidney. During cold storage (CS), residual oxygen is rapidly removed by ongoing metabolism. As a result, iron-dependent cold-induced injury might be limited during CS, since it is known that this damage is less under hypoxic conditions [5]. In contrast, during cold perfusion (CP), oxygen is constantly provided to the kidney and consequently iron-dependent coldinduced damage will be more pronounced. Moreover, during $\mathrm{CP}$ one is able to study pure cold-induced injury, since there is not a combination of cold and ischaemia, as in CS. 
We aimed to study iron-dependent cold-induced damage in the whole kidney. To this end, we studied the effects of iron chelation on the loss of kidney function after CP in the isolated perfused rat kidney (IPK). We compared it to the effects of iron chelation on kidney function after CS. The IPK was chosen as a model to realize cold preservation without preceding warm ischaemia, and to ensure that resulting damage will exclusively be caused by the cold (in the case of CP) or cold plus ischaemia (in case of CS). We designed this study to assess specifically the effects of (irondependent) cold-induced damage without ischaemia in a whole organ. In earlier studies, iron chelation was always applied in a combination of cold and ischaemia $[6,7]$, and a period of preceding warm ischaemia [8].

\section{Subjects and methods}

\section{Materials}

Pluronic F-108 was obtained from BASF (Arnhem, The Netherlands). Sodium pentobarbital was purchased from Sanofi Sante B.V. (Maassluis, The Netherlands), furosemide from Aventis Pharma B.V. (Hoevelaken, The Netherlands) and heparin from Leo Pharma B.V. (Weesp, The Netherlands). Travasol 8.5\% without electrolytes was from Baxter (Brussels, Belgium). University of Wisconsin (UW) solution (Viaspan) was obtained from Du Pont Pharma (Wilmington, Delaware, USA) and UW gluconate for machine perfusion was kindly provided by Dr Buurman (University Hospital Maastricht, The Netherlands) [9]. Na-penicillin was purchased from Yamanouchi (Leiderdorp, The Netherlands), insulin from Novo Nordisk Farma B.V. (Alphen a.d. Rijn, The Netherlands) and dexamethasone from Centrafarm (Etten-Leur, The Netherlands). ADH (lysine-vasopressin) was obtained from Sandoz (Bazel, Switzerland), aldosterone from Organon (Oss, The Netherlands), and angiotensin II from Beckman (Palo Alto, California, USA). All other chemicals were of analytical grade and obtained either from Sigma (St. Louis, MO, USA) or Merck AG (Darmstadt, Germany).

\section{Isolated perfused rat kidney}

Isolation of the rat kidney was performed as described in detail previously [10] with some minor alterations. Briefly, male Wistar-Hannover rats (220-280 g) were anaesthetized with pentobarbital $(6 \mathrm{mg} / 100 \mathrm{~g}$; i.p.). Subsequently, furosemide was injected i.p. $(1 \mathrm{mg} / 100 \mathrm{~g})$ to increase urine secretion. Heparin $(125 \mathrm{U} / 100 \mathrm{~g})$ was injected in the spleen. After canulation of the urether of the right kidney, the right renal artery was canulated via the mesenteric artery without interruption of flow. The kidney was excised and placed in a perfusion chamber with a constant temperature $\left(37.5\right.$ or $4^{\circ} \mathrm{C}$ during warm perfusion or cold preservation respectively). The perfusion buffer consisted of an isotonic cell-free Krebs-Ringer-Henseleit-based perfusate containing $25 \mathrm{~g} / 1$ Pluronic F-108, $112.0 \mathrm{mM} \mathrm{NaCl}, 5.2 \mathrm{mM} \mathrm{KCl}, 25.0 \mathrm{mM}$ $\mathrm{NaHCO}_{3}, 0.28 \mathrm{mM} \mathrm{KH} \mathrm{KO}_{4}, 0.84 \mathrm{mM} \mathrm{Na} \mathrm{HPO}_{4}, 4.0 \mathrm{mM}$ urea, $5.0 \mathrm{mM}$ glucose, $2.0 \mathrm{mM} \mathrm{CaCl}, 1.0 \mathrm{mM} \mathrm{MgCl}_{2}$, $0.50 \mathrm{mM}$ L-cysteine, $2.3 \mathrm{mM}$ glycine, $2.0 \mathrm{mM}$ Na-pyruvate, $1.2 \mathrm{mM}$ Na-acetate, $0.113 \mathrm{mM}$ Na-glutaminate, $0.21 \mathrm{mM}$
Na-propionate, $1.0 \mathrm{mM}$ inosine, $5.0 \mathrm{mM}$ alanine, $2.0 \mathrm{mM}$ glutamine, $1.2 \mathrm{mM} \alpha$-ketoglutarate, $0.01 \mathrm{mM}$ ascorbic acid, $0.32 \mathrm{ml} \mathrm{Na}$-lactate solution $(60 \%), 0.33 \mathrm{mM}$ glutathione, $0.08 \mathrm{mM}$ myo-inositol, $1 \mathrm{mg} / 1$ cholinechloride, 4 I.E./1 insulin, $2 \mu \mathrm{g} / 1$ aldosterone, $10 \mathrm{E} \mathrm{ADH}, 20 \mu \mathrm{E}$ angiotensin II. To this solution, $10 \mathrm{ml} 8.5 \%$ Travasol per litre, a mixture of 15 amino acids, was added. Pluronic F-108 was used as an oncotic agent in the albumin-free perfusion buffer. For the determination of glomerular filtration rate (GFR), vitamin $B_{12}(14 \mu \mathrm{M})$ was added to the perfusion buffer. The perfusate reservoir was placed in a waterbath of $37.5^{\circ} \mathrm{C}$ and was oxygenated with $95 \% \mathrm{O}_{2} / 5 \% \mathrm{CO}_{2}$.

\section{Preservation solutions}

UW solution and UW gluconate for machine perfusion, supplemented with $250 \mathrm{mg} / 1$ Na-penicillin, 48 I.u./1 insulin and $8.3 \mu \mathrm{M}$ dexamethasone, were used. The iron chelator $2,2^{\prime}$-dipyridyl $\left(2,2^{\prime}\right.$-DPD; $\left.100 \mu \mathrm{M}\right)$ or the negative control 4,4'-dipyridyl $\left(4,4^{\prime}\right.$-DPD; $\left.100 \mu \mathrm{M}\right)$ were added to the preservation solutions.

\section{Experimental protocols}

In the control group $(n=6)$, kidneys were perfused at $37.5^{\circ} \mathrm{C}$ with perfusion buffer $(500 \mathrm{ml})$ immediately after isolation. During a stabilization period of $30 \mathrm{~min}$, the perfusion flow was set to a value resulting in an arterial pressure of $75 \mathrm{mmHg}$ recorded just proximal to the kidney. After the first $200 \mathrm{ml}$ of venous effluent was discarded during the stabilization period, the perfusate was recirculated in the perfusion system.

In the experimental groups, kidneys were randomly distributed into the following experimental groups: CS with $2,2^{\prime}$-DPD $(n=6)$, CS with $4,4^{\prime}$-DPD $(n=6)$, CP with $2,2^{\prime}$-DPD $(n=6)$ and CP with $4,4^{\prime}$-DPD $(n=6)$. CS kidneys were flushed with cold $\left(4^{\circ} \mathrm{C}\right) \mathrm{UW}$ solution for $15 \mathrm{~min}$ with a perfusion flow of $2.2 \mathrm{ml} / \mathrm{min}$ and an arterial pressure between $40-60 \mathrm{mmHg}$, followed by $4 \mathrm{~h}$ storage at $4^{\circ} \mathrm{C}$. We also performed experiments with an extended period of CS. Kidneys were cold stored for $24 \mathrm{~h}$ in the presence of $2,2^{\prime}$-DPD $(n=7)$ or $4,4^{\prime}$-DPD $(n=3)$ or vehicle $(n=5)$. In addition, kidneys have been stored for $18 \mathrm{~h}$ at $4{ }^{\circ} \mathrm{C}$ in the presence $(n=3)$ or absence $(n=4)$ of the iron chelator desferal (deferoxamine, $0.625 \mathrm{mM}$ ). CP kidneys were perfused with $150 \mathrm{ml}$ cold $\left(4^{\circ} \mathrm{C}\right)$ UW gluconate for machine perfusion. During the first $15 \mathrm{~min}$ of perfusion of the CP kidneys the venous effluent was discarded, followed by recirculation of the solution in the perfusion system for $4 \mathrm{~h}$. Perfusion flow was set to a value resulting in an arterial pressure of $40-60 \mathrm{mmHg}$. At the end of the cold preservation period, the preservation solution of both CS and CP kidneys was replaced by $500 \mathrm{ml}$ perfusion buffer followed by reperfusion of the kidneys at $37.5^{\circ} \mathrm{C}$, like in control kidneys. After the $30 \mathrm{~min}$ stabilization period, urine samples were collected over $10 \mathrm{~min}$ intervals during $2 \mathrm{~h}$ of perfusion and used for functional analysis.

\section{Functional analysis}

During reperfusion, arterial pressure, GFR, diuresis and fractional water reabsorption $\left[\mathrm{FR}\left(\mathrm{H}_{2} \mathrm{O}\right)\right]$ were recorded continuously. Renal vascular resistance (RVR) and filtration fraction (FF) were calculated according to the following 
equations: $\mathrm{RVR}=$ arterial pressure/perfusion flow; $\mathrm{FF}=$ $\mathrm{GFR} /$ perfusion flow. Urine and perfusate samples were analysed for glucose, sodium, and the enzyme alkaline phosphatase (ALP). Sodium was determined by flame photometry. The GLUCO-QUANT glucose kit from Roche Diagnostics (Almere, the Netherlands) was used for glucose analysis. ALP excretion, used as a measure for proximal tubular injury, was measured by spectrophotometry.

\section{Histology}

At the end of the $2 \mathrm{~h}$ reperfusion period, samples from control and experimental kidneys were collected. The samples were fixed with bouin (25\% formaldehyde of a $37 \%$ solution, $70 \%$ picric acid, 5\% acetic acid) and embedded in paraffin. Kidney sections were stained with haematoxylin and eosin and assessed by light microscopy.

\section{Data analysis}

Data are expressed as mean $\pm \mathrm{SE}$ of 6 kidneys in each group, unless otherwise stated. Data obtained from two groups were compared by ANOVA for repeated measures with time as within-subject factor and treatment group as between-subject factor. Differences were considered significant if $P<0.05$.

\section{Results}

Compared to $37.5^{\circ} \mathrm{C}$ control perfusion, $4 \mathrm{~h}$ cold preservation of the IPK resulted in a decrease in kidney function during reperfusion after both $\mathrm{CS}$ and CP $(P<0.05$ for control vs 4,4'-DPD). Figure 1 shows the results of CS kidneys in the presence of the iron chelator 2,2'-DPD or the negative control 4,4'-DPD. CS kidneys in the presence of $4,4^{\prime}$-DPD showed a decrease in GFR and $\mathrm{FR}\left(\mathrm{H}_{2} \mathrm{O}\right)$, and an increase in fractional glucose excretion (FE(gluc)) and $\mathrm{FE}(\mathrm{Na})$ compared to control $(P<0.05)$. No significant difference in diuresis, RVR, FF and the release of ALP was seen after CS when compared to control. Figure 2 shows the results of $\mathrm{CP}$ in the presence of $2,2^{\prime}$-DPD or 4,4'-DPD. CP kidneys with 4,4'-DPD showed an increase in RVR, FE(Na) and FE(gluc), and a decrease
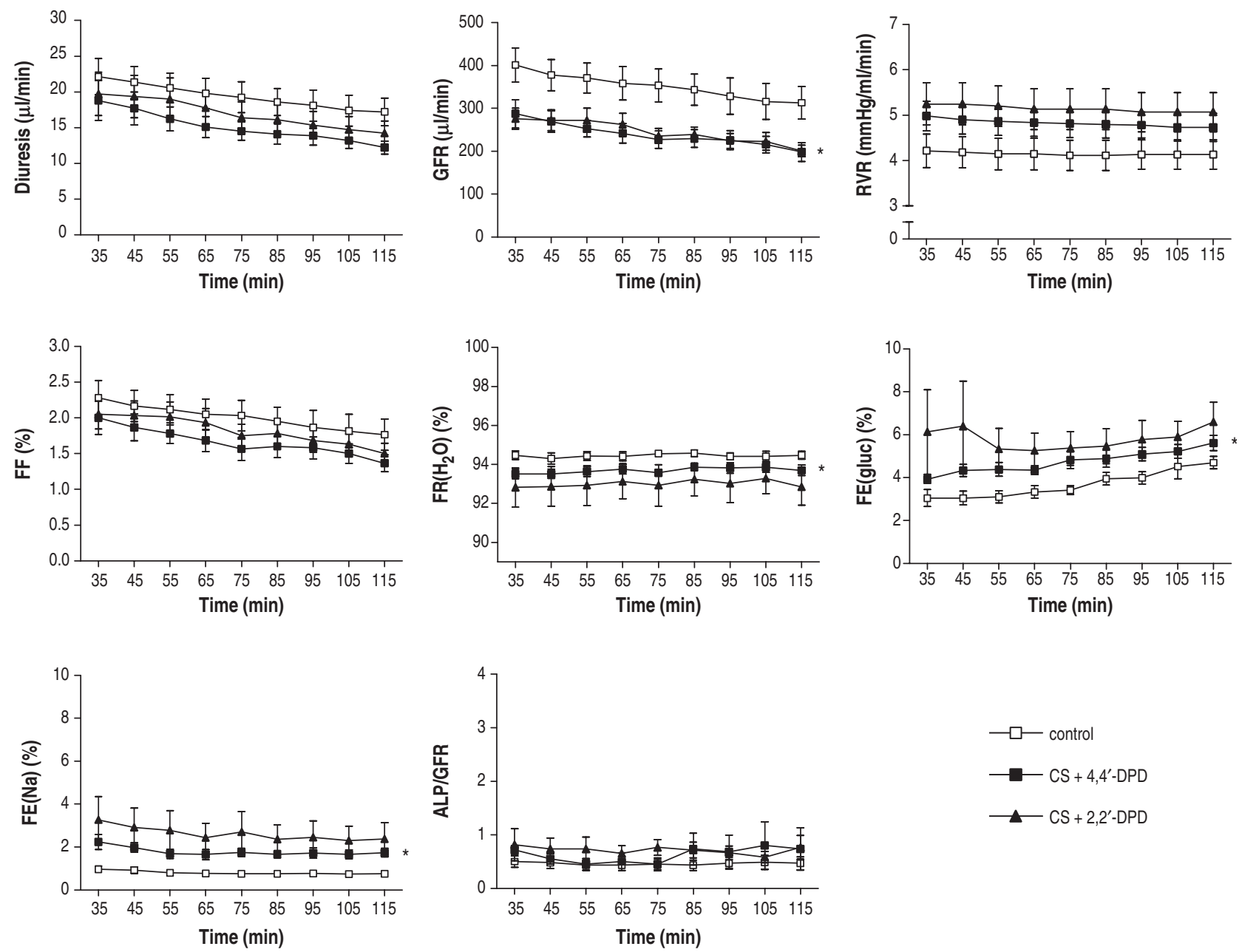

Fig. 1. Diuresis, GFR, RVR, FF, FR( $\left.\mathrm{H}_{2} \mathrm{O}\right), \mathrm{FE}(\mathrm{gluc}), \mathrm{FE}(\mathrm{Na})$, and the release of ALP/GFR as a function of time during $2 \mathrm{~h}$ reperfusion after $4 \mathrm{~h}$ cold $\left(4^{\circ} \mathrm{C}\right)$ storage $(\mathrm{CS})$ in UW solution. The iron chelator $2,2^{\prime}$-DPD $(100 \mu \mathrm{M} ; \boldsymbol{\Delta})$ or the negative control 4,4'-DPD $(100 \mu \mathrm{M}$; $\boldsymbol{\square})$ were added to the UW solution. Kidney function after CS was compared to control perfusion without prior cold preservation (control; $\square$ ). All data are means \pm SE of 6 experiments. *Significantly different from control $(P<0.05)$. 

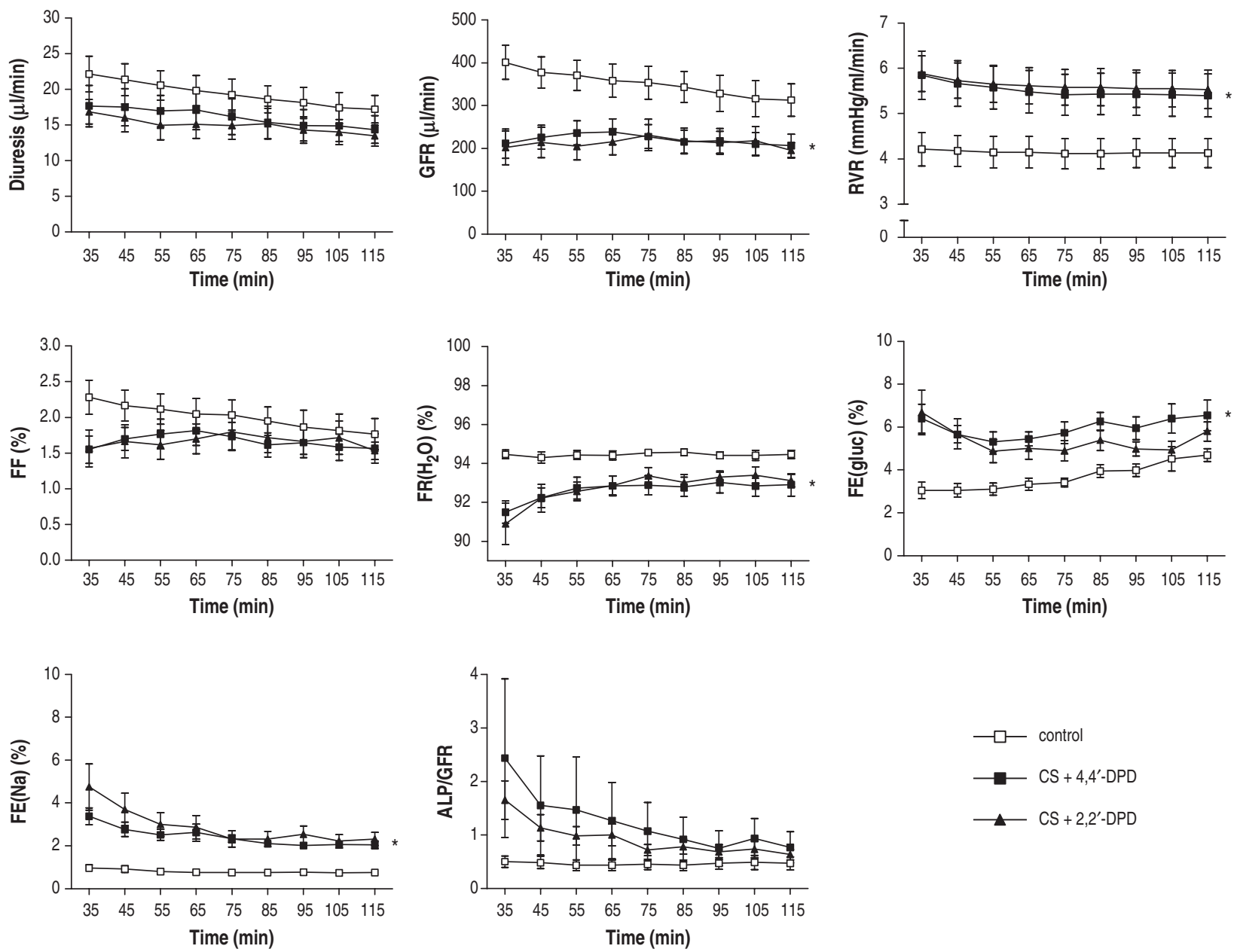

Fig. 2. Diuresis, GFR, RVR, FF, FR( $\left.\mathrm{H}_{2} \mathrm{O}\right), \mathrm{FE}(\mathrm{gluc}), \mathrm{FE}(\mathrm{Na})$, and the release of ALP/GFR as a function of time during $2 \mathrm{~h}$ reperfusion after $4 \mathrm{~h}$ cold $\left(4^{\circ} \mathrm{C}\right)$ perfusion $(\mathrm{CP})$ in UW solution for machine perfusion. The iron chelator $2,2^{\prime}$-DPD $(100 \mu \mathrm{M}$; $\boldsymbol{\Delta})$ or the negative control $4,4^{\prime}$-DPD $(100 \mu \mathrm{M} ; \mathbf{\square})$ were added to the UW solution. Kidney function after CP was compared to control perfusion without prior cold preservation (control; $\square$ ). All data are means \pm SE of six experiments. *Significantly different from control $(P<0.05)$.

in GFR and $\mathrm{FR}\left(\mathrm{H}_{2} \mathrm{O}\right)$ compared to control kidneys $(P<0.05)$. No significant difference in diuresis, $\mathrm{FF}$ and the release of ALP was seen after CP when compared to control. Addition of the iron chelator 2,2'-DPD to the preservation solution did not prevent the decrease in kidney function after either $4 \mathrm{~h} \mathrm{CS}$ or $4 \mathrm{~h} \mathrm{CP}$ ( $P>0.05$ for $4,4^{\prime}$-DPD vs $2,2^{\prime}$-DPD).

We also performed experiments using $24 \mathrm{~h}$ of CS. In these experiments, in the control CS group either $4,4^{\prime}$-DPD or vehicle was added to exclude a possible toxic effect of $4,4^{\prime}$-DPD. There was no difference between these two groups (data not shown). Figure 3 shows the results of kidneys cold stored for $24 \mathrm{~h}$ in the presence $(n=7)$ or absence $(n=8)$ of $2,2^{\prime}$-DPD. Compared to warm control perfusion, $24 \mathrm{~h} \mathrm{CS}$ in the absence of 2,2'-DPD resulted in a decrease in GFR and $\mathrm{FR}\left(\mathrm{H}_{2} \mathrm{O}\right)$, and an increase in diuresis, RVR, FF and FE(gluc) $(P<0.05)$. ALP excretion per 10 min was not significantly different from warm control. However, cumulative ALP excretion was higher in both experimental groups compared to warm control (data not shown). Addition of the iron chelator 2,2'-DPD to the preservation solution did not prevent the decrease in kidney function after $24 \mathrm{~h}$ CS $(P>0.05$ for CS vs $\mathrm{CS}+2,2^{\prime}$-DPD). When $24 \mathrm{~h}$ of $\mathrm{CS}$ plus $2,2^{\prime}$-DPD $(n=7)$ was compared to either $4,4^{\prime}$-DPD $(n=3)$ or vehicle $(n=5)$, the results were the same.

During our study, we also performed experiments using the iron chelator desferal. Figure 4 shows the results for kidneys cold stored for $18 \mathrm{~h}$ in the presence $(n=3)$ or absence $(n=4)$ of $0.625 \mathrm{mM}$ desferal. CS control kidneys showed a decrease in GFR, FF and $\mathrm{FR}\left(\mathrm{H}_{2} \mathrm{O}\right)$, and an increase in RVR, FE(gluc), $\mathrm{FE}(\mathrm{Na})$ and the release of ALP compared to warm control perfusion $(n=6 ; P<0.05)$. No significant difference in diuresis was seen after CS when compared to control. Addition of desferal to the preservation solution did not prevent the decrease in kidney function after $18 \mathrm{~h}$ CS $(P>0.1$ for CS vs CS + desferal).

Histological analysis of kidneys after $4 \mathrm{~h}$ of $\mathrm{CS}$ or CP, with either $4,4^{\prime}$-DPD or $2,2^{\prime}$-DPD, showed similar features consistent with mild tubular epithelial damage, i.e. distension with flattening of tubular epithelium, nuclear activation and fine vacuolation of 

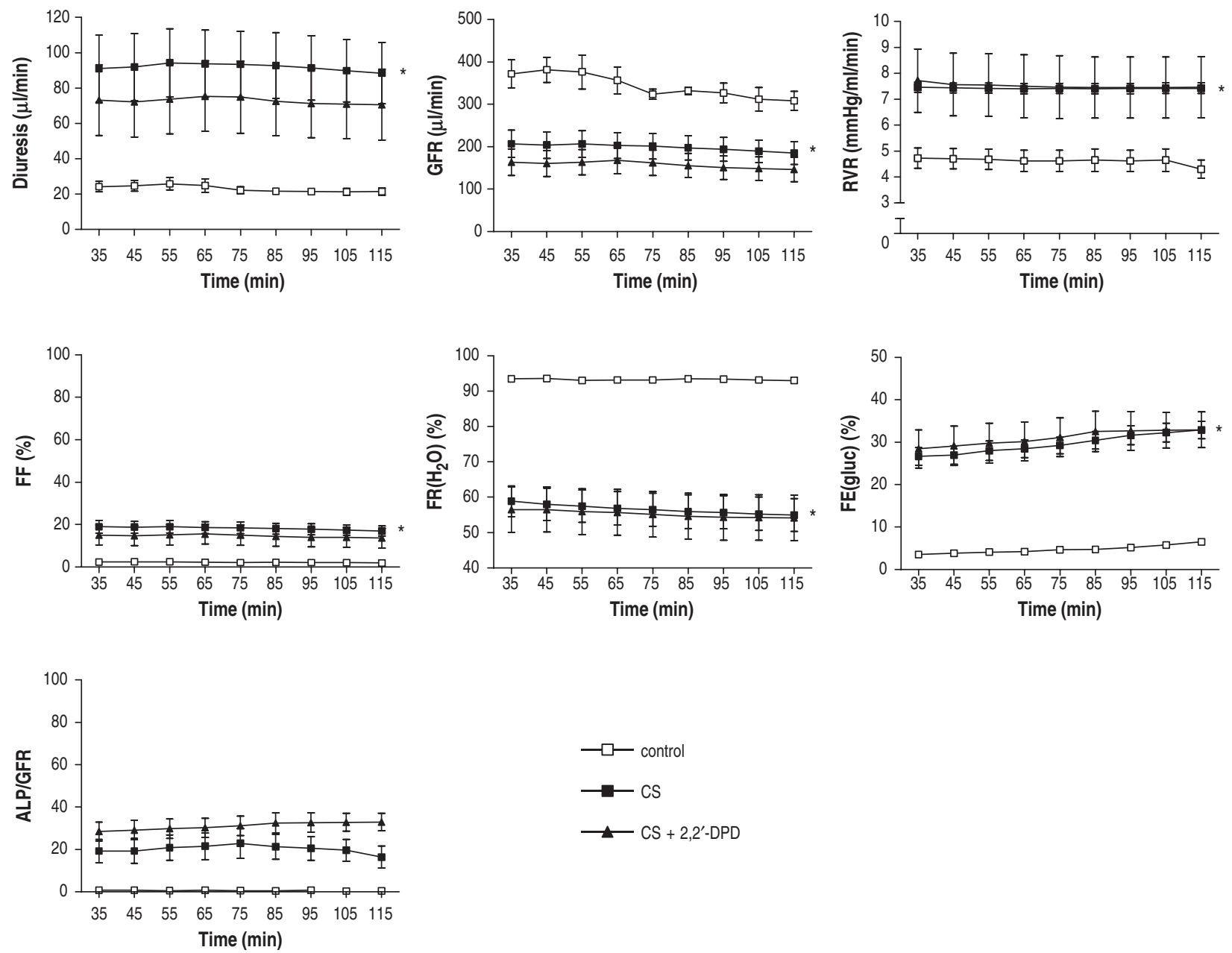

Fig. 3. Diuresis, GFR, RVR, FF, FR( $\left.\mathrm{H}_{2} \mathrm{O}\right), \mathrm{FE}(\mathrm{gluc})$, and the release of $\mathrm{ALP} / \mathrm{GFR}$ as a function of time during $2 \mathrm{~h}$ reperfusion after $24 \mathrm{~h}$ cold $\left(4^{\circ} \mathrm{C}\right)$ storage $(\mathrm{CS})$ in $\mathrm{UW}$ solution in the presence $(n=7 ; \boldsymbol{\Delta})$ or absence $(n=8 ; \boldsymbol{\square})$ of the iron chelator $2,2^{\prime}$-DPD $(100 \mu \mathrm{M})$. Kidney function after CS was compared to control perfusion without prior cold preservation (control; $n=4$; $\square$ ). Data are presented as means $\pm \mathrm{SE}$ of $\mathrm{n}$ experiments. ${ }^{*}$ Significantly different from control $(P<0.05)$.

the cytoplasm. The brush border remained intact and there was no luminal cellular debris. After $24 \mathrm{~h}$ of CS, damage was more severe. There was prominent nuclear activation, irregular vacuolation of the cytoplasm, irregular spacing of nuclei, and loss of the brush border with cellular debris in tubular lumens (Figure 5).

\section{Discussion}

During this study, we investigated whether irondependent cold-induced damage contributes to injury during cold kidney preservation, which is especially important for $\mathrm{CP}$ by machine perfusion. Injury during $\mathrm{CP}$ results from pure hypothermia. The iron-dependent cold-induced damage imposed by $\mathrm{CP}$ may be more pronounced than iron-dependent cold-induced damage during CS. During CS, residual oxygen will be removed by ongoing metabolism, but during $\mathrm{CP}$ oxygen is constantly delivered to the organ. It is known that hypoxia reduces iron-dependent cold-induced damage in vitro [5]. In a recent review, it was described that machine perfusion and CS of human kidney transplants have similar long-term outcomes [11]. It is, however, imaginable that possible beneficial effects of $\mathrm{CP}$ are hampered by the deleterious effects of iron-dependent cold-induced damage, which might be prevented by the addition of an iron chelator. Our study does not support this notion. Compared to control perfusion, cold preservation of the IPK for $4 \mathrm{~h}$ resulted in a decrease in kidney function during reperfusion after both CS and CP (Figures 1 and 2). After 18 and $24 \mathrm{~h}$ of CS (Figures 3 and 4), this decrease in function during reperfusion was even more pronounced than after $4 \mathrm{~h}$ of cold preservation. Addition of the iron chelator 2,2'-DPD to the preservation solution UW did not improve kidney function or histology of proximal tubules after both CS and CP for $4 \mathrm{~h}$ and after CS for $24 \mathrm{~h}$. The iron chelator desferal was also unable to prevent the decrease in kidney function during reperfusion after $18 \mathrm{~h} \mathrm{CS}$. 

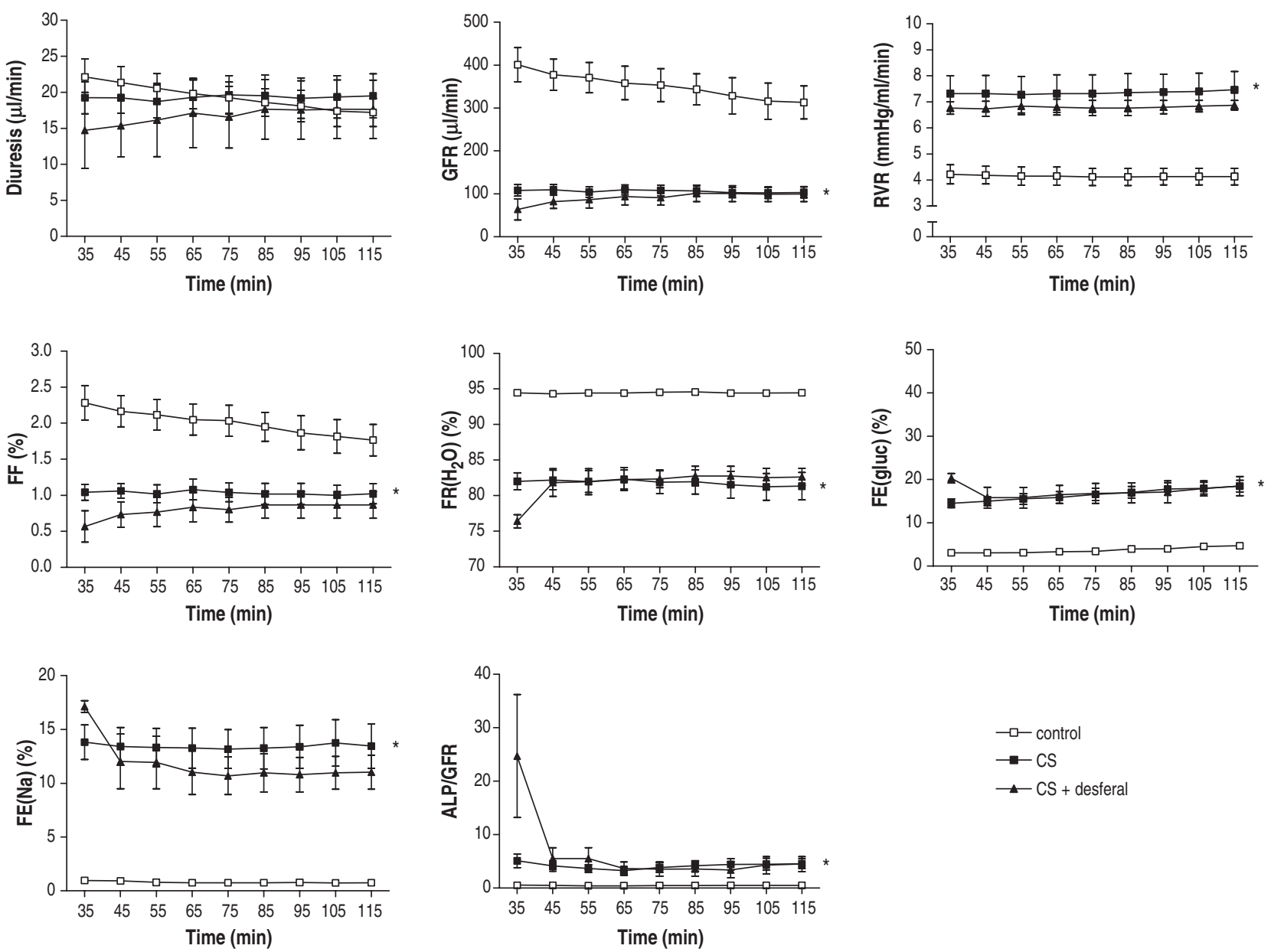

Fig. 4. Diuresis, GFR, RVR, FF, FR( $\left.\mathrm{H}_{2} \mathrm{O}\right), \mathrm{FE}(\mathrm{gluc}), \mathrm{FE}(\mathrm{Na})$, and the release of $\mathrm{ALP} / \mathrm{GFR}$ as a function of time during $2 \mathrm{~h}$ reperfusion after $18 \mathrm{~h}$ cold $\left(4{ }^{\circ} \mathrm{C}\right)$ storage $(\mathrm{CS})$ in UW solution in the presence $(n=3 ; \boldsymbol{\Delta})$ or absence $(n=4 ; \boldsymbol{\square})$ of the iron chelator desferal $(0.625 \mathrm{mM})$. Kidney function after CS was compared to control perfusion without prior cold preservation (control; $n=6$; $\square$ ). Data are presented as means $\pm \mathrm{SE}$ of $\mathrm{n}$ experiments. *Significantly different from control $(P<0.05)$.

In most studies, long-term ( $24 \mathrm{~h}) \mathrm{CS}$ of kidneys is applied. This leads to a dramatic decrease in function, and to practically non-functioning kidneys with a residual GFR of about $10 \%$ [12]. We decided to study short-term $(4 \mathrm{~h})$ cold kidney preservation and an extended period of CS (i.e. $24 \mathrm{~h}$ ). We argued that studying $4 \mathrm{~h}$ of cold preservation might be more sensitive than $24 \mathrm{~h}$, since the damage is more subtle. Already after $2 \mathrm{~h}$ of $\mathrm{CS}$, mitochondrial changes are found in vitro [13]. Mitochondria are thought to play a central role in the mechanism of cold storage [14]. Because PTC are completely dependent on oxidative phosphorylation, mitochondrial dysfunction will lead to functional changes of the kidney, indicative of PTC impairment, such as an increased FE(gluc). Moreover, it has been found in rats that $4 \mathrm{~h}$ of CS leads to considerable damage in a rat kidney transplantation model [15]. One should, of course, be aware that our model is far from clinical conditions, particularly marginal donors, where there is also considerable damage before the cold preservation. So, our model offers the advantage of selectively studying cold-induced damage in a whole kidney model, which limits its applicability in clinical practice.

In addition to the experiments with $2,2^{\prime}$-DPD and its negative control 4,4'-DPD, experiments have been done using the iron chelator desferal. During these experiments, kidneys were cold stored for $18 \mathrm{~h}$ in the presence or absence of $0.625 \mathrm{mM}$ desferal. Similar conditions were used in the study of Huang et al. [8] in which it was shown that inclusion of desferal in the cold storage solution UW reduces cold ischaemiaassociated renal transplant damage and improves renal function of rat kidney transplants.

Our data show that iron chelation does not prevent deterioration of kidney function after cold preservation of the kidney. In the literature, many studies have shown the beneficial effect of iron chelation on cold preservation. Most of these studies have been performed in vitro, and in this setting the effect is unequivocal [1,3-5]. Our study casts doubt on the effect of iron chelation on cold-induced damage in vivo. In the past, this effect has been found in vivo. During CS of rabbit kidneys, prevention of lipid peroxidation 


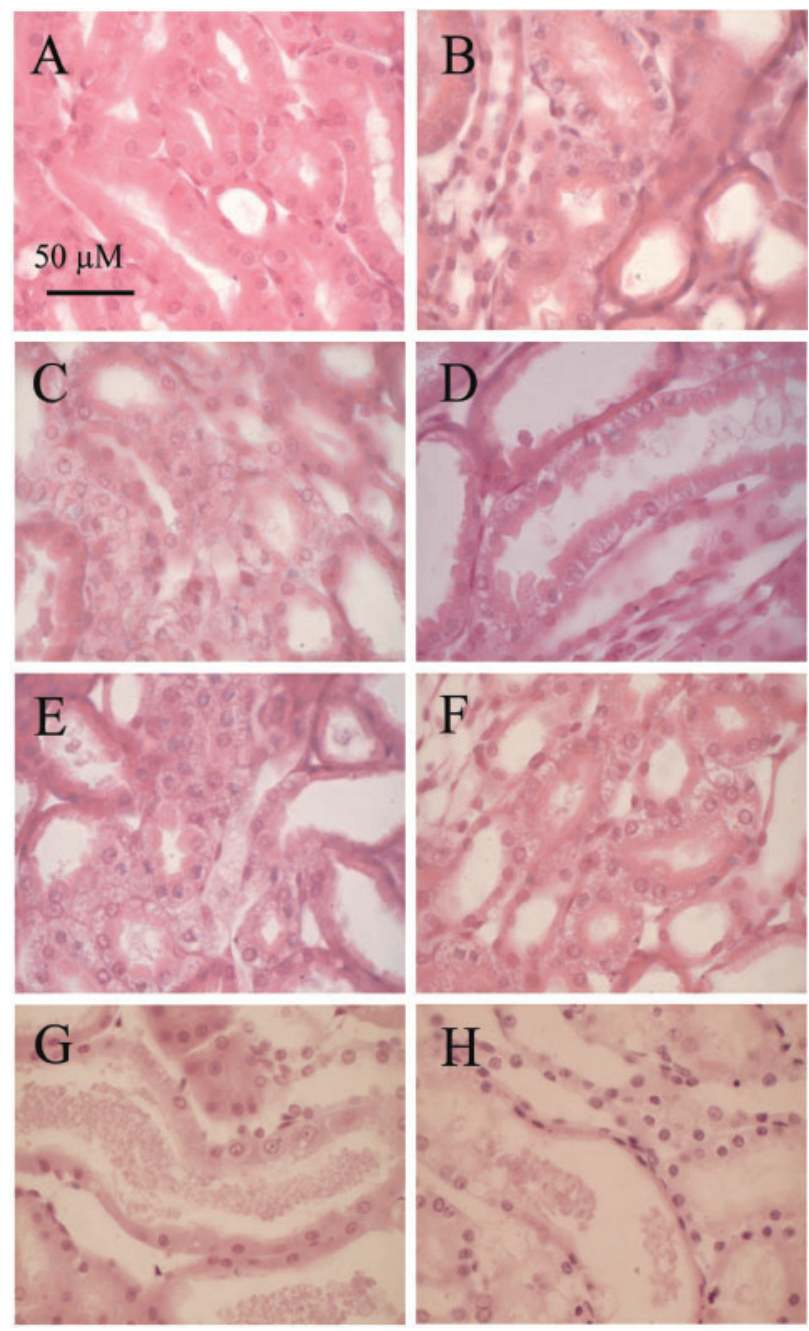

Fig. 5. Representative examples of histology of proximal tubules in the outer stripe of the outer medulla of (A) normal rat kidney, and of the isolated perfused rat kidney (IPK) after: (B) $2 \mathrm{~h}$ control perfusion $\left(37^{\circ} \mathrm{C}\right)$; (C) $4 \mathrm{~h}$ cold storage $(\mathrm{CS})$ with $4,4^{\prime}$-DPD $(100 \mu \mathrm{M})$ plus $2 \mathrm{~h}$ reperfusion $\left(37^{\circ} \mathrm{C}\right)$; (D) $4 \mathrm{~h}$ CS with $2,2^{\prime}$-DPD $(100 \mu \mathrm{M})$ plus $2 \mathrm{~h}$ reperfusion; (E) $4 \mathrm{~h}$ cold perfusion (CP) with 4,4'-DPD plus $2 \mathrm{~h}$ reperfusion; (F) $4 \mathrm{~h} \mathrm{CP}$ with $2,2^{\prime}$-DPD plus $2 \mathrm{~h}$ reperfusion; (G) $24 \mathrm{~h}$ CS with $4,4^{\prime}$-DPD plus $2 \mathrm{~h}$ reperfusion; (H) $24 \mathrm{~h}$ CS with $2,2^{\prime}$-DPD plus $2 \mathrm{~h}$ reperfusion. Proximal tubules in samples B-F show similar features, i.e. distended tubules with intact brush borders and non-distended tubules with vacuolization and some tubular debris. After $24 \mathrm{~h}$ of CS (samples G and H) there is loss of brush border and widespread tubular debris in the lumina. Magnification $260 \times$.

by iron chelation was described [6,7]. Very recently, Huang et al. showed that the addition of the iron chelator desferal during CS of a syngeneic rat kidney transplantation model improved kidney function after transplantation considerably [8]. However, in all of these models there is a combination of cold and ischaemia, rather than pure cold-induced injury. So, in these studies it is possible that the iron chelator has its beneficial effects on ischaemia-reperfusion injury rather than on the cold. It has been described before that iron chelators are able to prevent damage induced by ischaemia-reperfusion [16,17]. Secondly, since in our model no leucocytes are added to the perfusate, it is possible that we overlook effects of the iron chelator on the endothelium. It is possible that iron chelation has an effect on the endothelium and that upregulation of adhesion molecules and subsequent leucocyte adhesion is prevented. In warm ischaemia/reflow, adhesion of leucocytes plays an important role. Treatment with anti-ICAM-1 decreases damage [18] and also ICAM-1deficient mice are protected against damage inflicted by warm ischaemia/reflow [19]. Iron-dependent coldinduced damage has been described in cultured liver endothelial cells [1]. It is possible that endothelial cell stress leads to expression of adhesion molecules. In a previous study, we did not find alteration of vascular function (both endothelium-dependent and -independent) in renal vessels [20], but this does not exclude the possibility that iron-dependent coldinduced damage leads to upregulation of adhesion molecules in these cells that may be prevented by iron chelation. Prevention of endothelial damage might also explain the decrease of lipid peroxidation in stored rabbit kidneys [6,7].

Our study shows that iron chelation is not able to prevent cold-induced damage imposed by CS or CP to PTC in the isolated perfused rat kidney. Although very effective in vitro, iron chelation did not infer protection. However, this does not mean that iron chelators should not be added to the preservation solution. Iron chelation might be beneficial by other mechanisms than inhibition of iron-dependent coldinduced damage of PTC.

Acknowledgements. UW gluconate for machine perfusion was kindly provided by Dr Buurman, University Hospital Maastricht (Maastricht, The Netherlands). The care and use of animals described in this investigation was approved by the ethical committee of the Radboud University Nijmegen Medical Centre.

Conflict of interest statement. None declared.

\section{References}

1. Rauen U, Elling B, Gizewski ER et al. Involvement of reactive oxygen species in the preservation injury to cultured liver endothelial cells. Free Radic Biol Med 1997; 22: 17-24

2. Mathew AJ, Hollister WR, Addona T, Baust JG, Van Buskirk RG. Vitamin E and EDTA improve the efficacy of hypothermosol-implication of apoptosis. Vitr Mol Toxicol 1999; 12: 163-172

3. Kerkweg U, Li T, de Groot H, Rauen U. Cold-induced apoptosis of rat liver cells in University of Wisconsin solution: The central role of chelatable iron. Hepatology 2002; 35: $560-567$

4. Bartels-Stringer M, Kramers C, Wetzels JFM et al. Hypothermia causes a marked injury to rat proximal tubular cells that is aggravated by all currently used preservation solutions. Cryobiology 2003; 47: 82-91

5. Rauen U, Polzar B, Stephan H, Mannherz HG, de Groot H. Cold-induced apoptosis in cultured hepatocytes and liver endothelial cells: mediation by reactive oxygen species. FASEB $J$ 1999; 13: 155-168

6. Fuller BJ, Lunec J, Healing G, Simpkin S, Green CJ. Reduction of susceptibility to lipid peroxidation by desferrioxamine in 
rabbit kidneys subjected to 24-hour cold ischaemia and reperfusion. Transplantation 1987; 43: 604-606

7. Gower JD, Healing G, Fuller BJ, Simpkin S, Green CJ. Protection against oxidative damage in cold-stored rabbit kidneys by desferrioxamine and indomethacin. Cryobiology 1989; 26: 309-317

8. Huang H, He Z, Roberts J, Salahudeen AK. Deferoxamine reduces cold-ischemic renal injury in a syngeneic kidney transplant model. Am J Transplant 2003; 3: 1531-1537

9. Daemen JW, Oomen AP, Janssen MA et al. Glutathione S-transferase as predictor of functional outcome in transplantation of machine-preserved non-heart-beating donor kidneys. Transplantation 1997; 63: 89-93

10. Cox PG, Moons MM, Slegers JF, Russel FG, van Ginneken CA. Isolated perfused rat kidney as a tool in the investigation of renal handling and effects of nonsteroidal antiinflammatory drugs. J Pharmacol Methods 1990; 24: 89-103

11. Wight JP, Chilcott JB, Holmes MW, Brewer N. Pulsatile machine perfusion $v s$ cold storage of kidneys for transplantation: a rapid and systematic review. Clin Transplant 2003; 17: 293-307

12. Ramella SG, Hadj Aissa A, Barbieux A et al. Evaluation of a high sodium-low potassium cold-storage solution by the isolated perfused rat kidney technique. Nephrol Dial Transplant 1995; 10: 842-846

13. Salahudeen AK, Huang H, Joshi M, Moore NA, Jenkins JK. Involvement of the mitochondrial pathway in cold storage and rewarming-associated apoptosis of human renal proximal tubular cells. Am J Transplant 2003; 3: 273-280

14. Rauen U, de Groot H. Mammalian cell injury induced by hypothermia - the emerging role for reactive oxygen species. Biol Chem 2002; 383: 477-488

15. Tullius SG, Nieminen-Kelha M, Buelow R et al. Inhibition of ischaemia/reperfusion injury and chronic graft deterioration by a single-donor treatment with cobalt-protoporphyrin for the induction of heme oxygenase-1. Transplantation 2002; 74: 591-598

16. Gonzalez-Fajardo JA, Fernandez L, Alvarez T, Vaquero C. Preservation of cortical microcirculation after kidney ischaemia-reperfusion: value of an iron chelator. Annu Vasc Surg 1995; 9: 227-228

17. Liachenko S, Tang P, Xu Y. Deferoxamine improves early postresuscitation reperfusion after prolonged cardiac arrest in rats. J Cereb Blood Flow Metab 2003; 23: 574-581

18. Kelly KJ, Williams WW, Colvin RB, Bonventre JV. Antibody to intercellular adhesion molecule 1 protects the kidney against ischemic injury. Proc Natl Acad Sci USA 1994; 91: 812-816

19. Kelly KJ, Williams WW, Colvin RB et al. Intercellular adhesion molecule-1-deficient mice are protected against ischemic renal injury. J Clin Invest 1996; 97: 1056-1063

20. Bartels-Stringer M, Terlunen L, Siero $\mathrm{H}$ et al. Preserved vascular reactivity of rat renal arteries after cold storage. Cryobiology 2004; 48: 95-98 